\title{
Exciton Delocalization in $\mathrm{H}_{2} \mathrm{OBPc}_{1-\mathrm{x}} \mathrm{MOBPc}_{\mathrm{x}}(\mathrm{M}=\mathrm{Co}, \mathrm{Cu}, \mathrm{Ni}$, Mn) Crystalline Thin Film Organic Alloys
}

Lane W. Manning, Naveen Rawat, Cody Lamarche, Rory Waterman, Randall L. Headrick, Madalina Furis*

L.W. Manning, Dr. N. Rawat,

Prof. R.L. Headrick, Prof. M. Furis

Materials Science Program and Department of Physics

University of Vermont, 82 University Place, Burlington, VT, 05405, U.S.

E-mail: madalina.furis@uvm.edu Telephone: (802) 6565177

Prof. R. Waterman

Department of Chemistry

University of Vermont, 82 University Place, Burlington, VT, 05405, U.S.

C. Lamarche

Department of Astrophysics

Cornell University, 108 Space Sciences Building, Ithaca, NY 14853, U.S. 


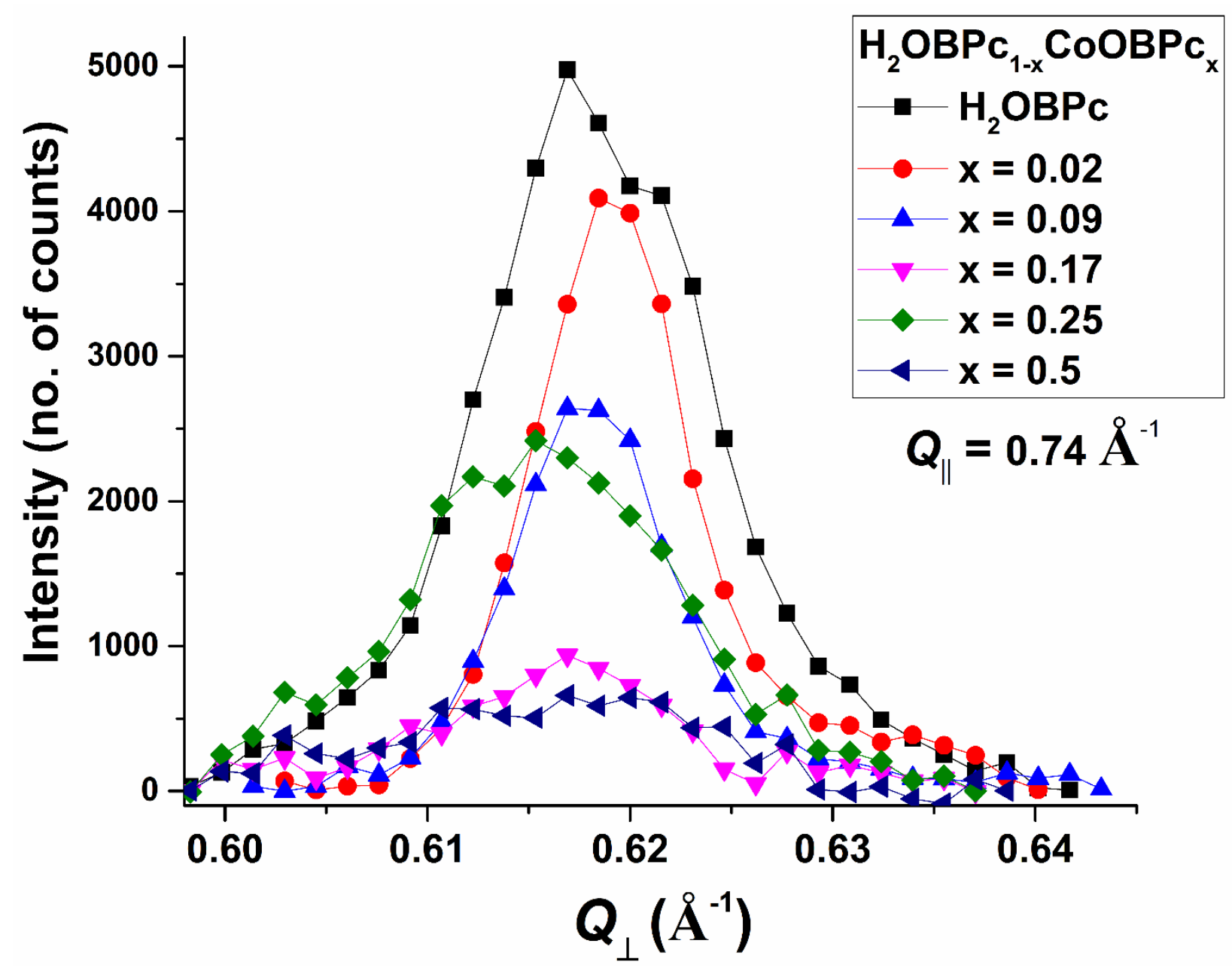

Figure S1. (110) $\mathrm{H}_{2} \mathrm{OBPc}$ GIXRD Peak Intensity vs. Q perpendicular for varying concentrations of $\mathrm{H}_{2} \mathrm{OBP}_{1-\mathrm{x}} \mathrm{CoOBP}_{\mathrm{x}}$ thin film samples. The plot was generated from the scattering map in Figure 7 (main text) by horizontally binning twenty pixels centered at $Q_{/ /}=0.74 \AA^{-1}$. 


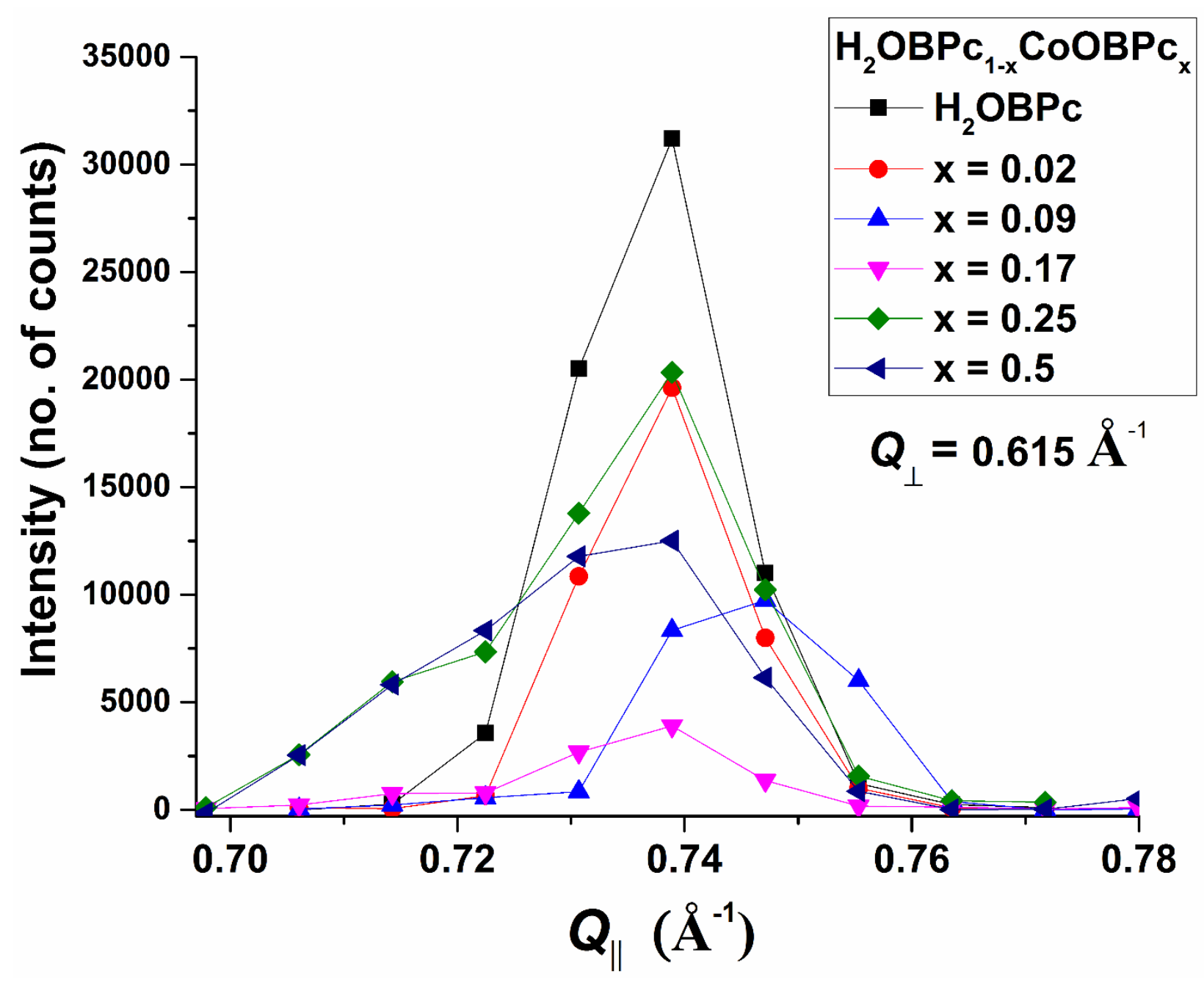

Figure S2. (110) $\mathrm{H}_{2} \mathrm{OBPc}$ GIXRD Peak Intensity vs. Q parallel for varying concentrations of $\mathrm{H}_{2} \mathrm{OBP}_{1-\mathrm{x}} \mathrm{CoOBP}_{\mathrm{x}}$ thin film samples. The plot was generated from the scattering map in Figure 7 (main text) by vertically binning ten pixels centered at $Q_{\perp}=0.615 \AA^{-1}$. 


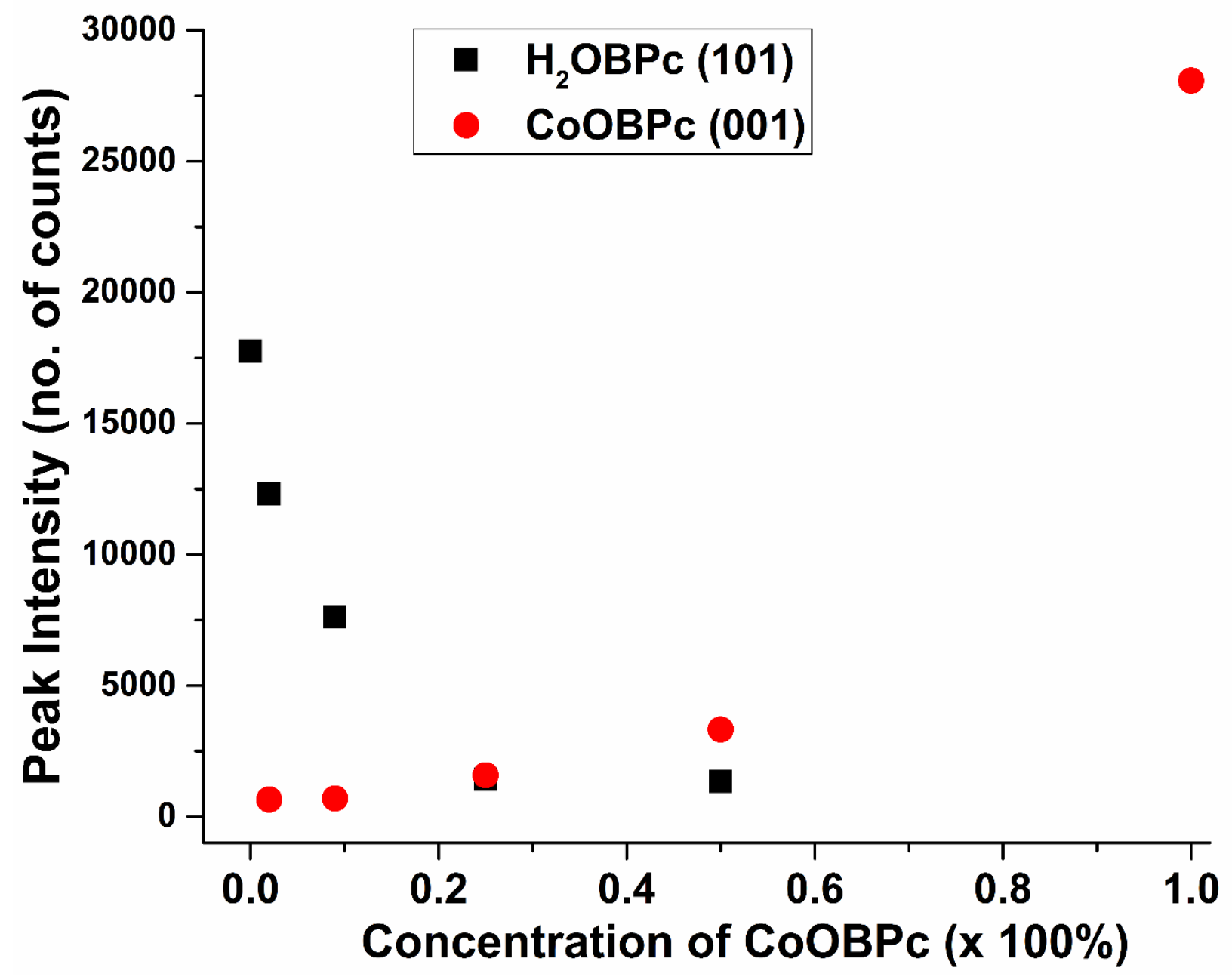

Figure S3. Peak GIXRD Reflection Intensity vs. Concentration of CoOBPc for the (101) reflection of $\mathrm{H}_{2} \mathrm{OBPc}$ and the (001) reflection of CoOBPc in $\mathrm{H}_{2} \mathrm{OBPc}_{1-\mathrm{x}} \mathrm{CoOBP}_{\mathrm{x}}$ thin film samples. 


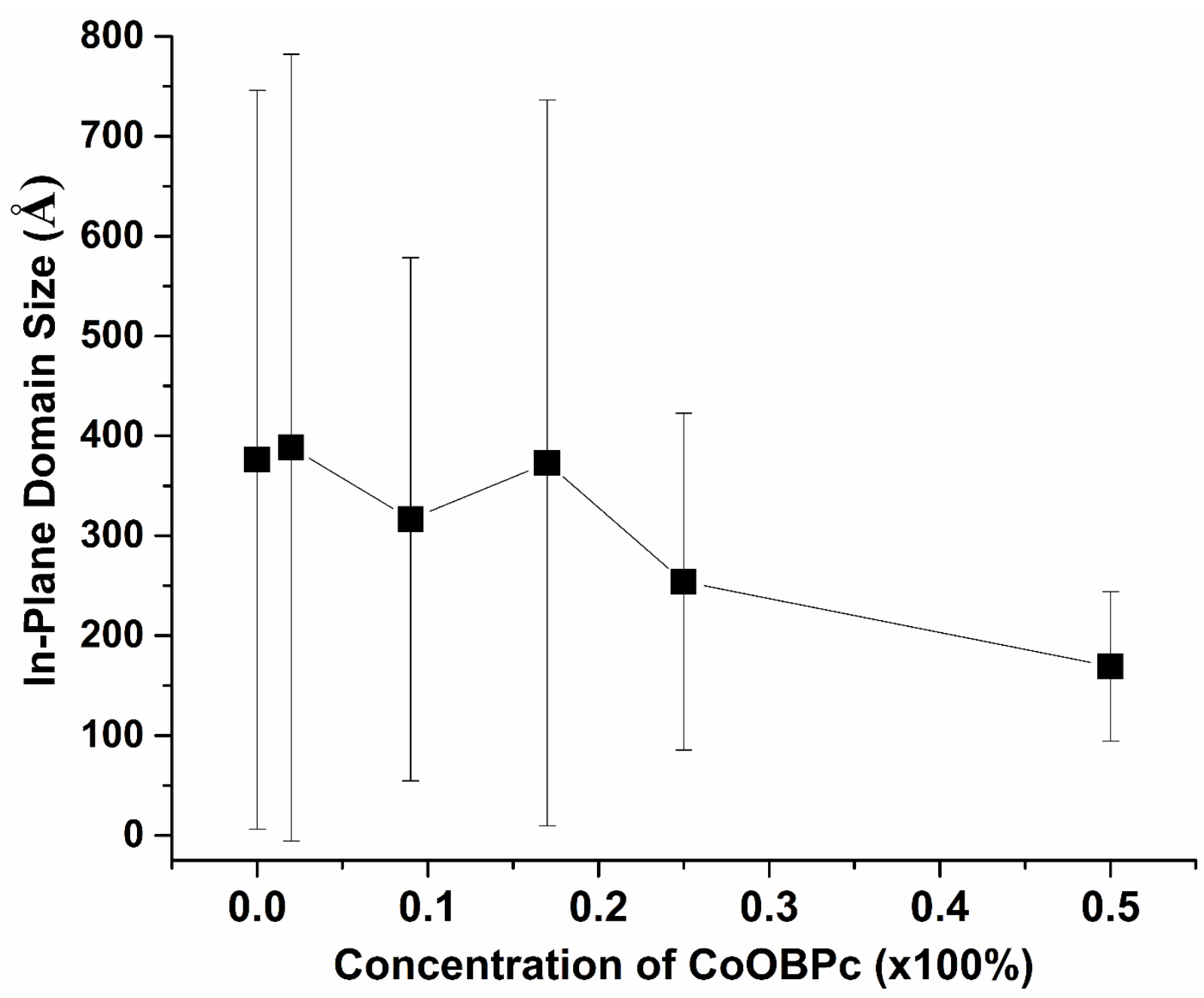

Figure S4. Estimated in-plane domain size vs. concentration of CoOBPc for the (110) GIXRD reflections of $\mathrm{H}_{2} \mathrm{OBP}_{1-\mathrm{x}} \mathrm{CoOBP}_{\mathrm{x}}$ crystalline thin film samples. Error bars are on the order of the estimated domain sizes, as a result of the resolution limit of the experiment. 


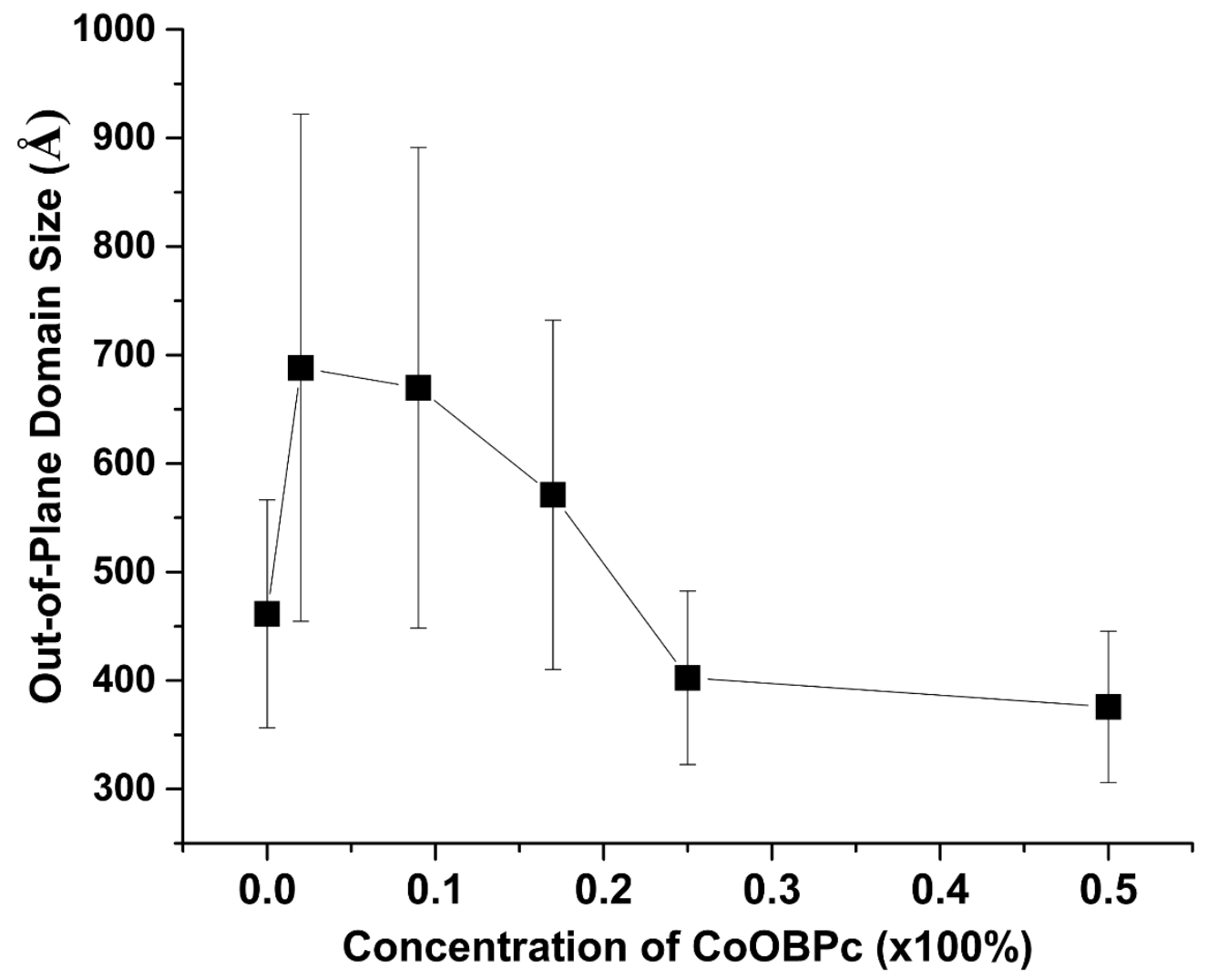

Figure S5. Estimated out-of-plane domain size vs. concentration of CoOBPc for the (110) GIXRD reflections of $\mathrm{H}_{2} \mathrm{OBP}_{1-\mathrm{x}} \mathrm{CoOBP}_{\mathrm{x}}$ crystalline thin film samples. Error bars are on the order of the estimated domain sizes, as a result of the resolution limit of the experiment. 

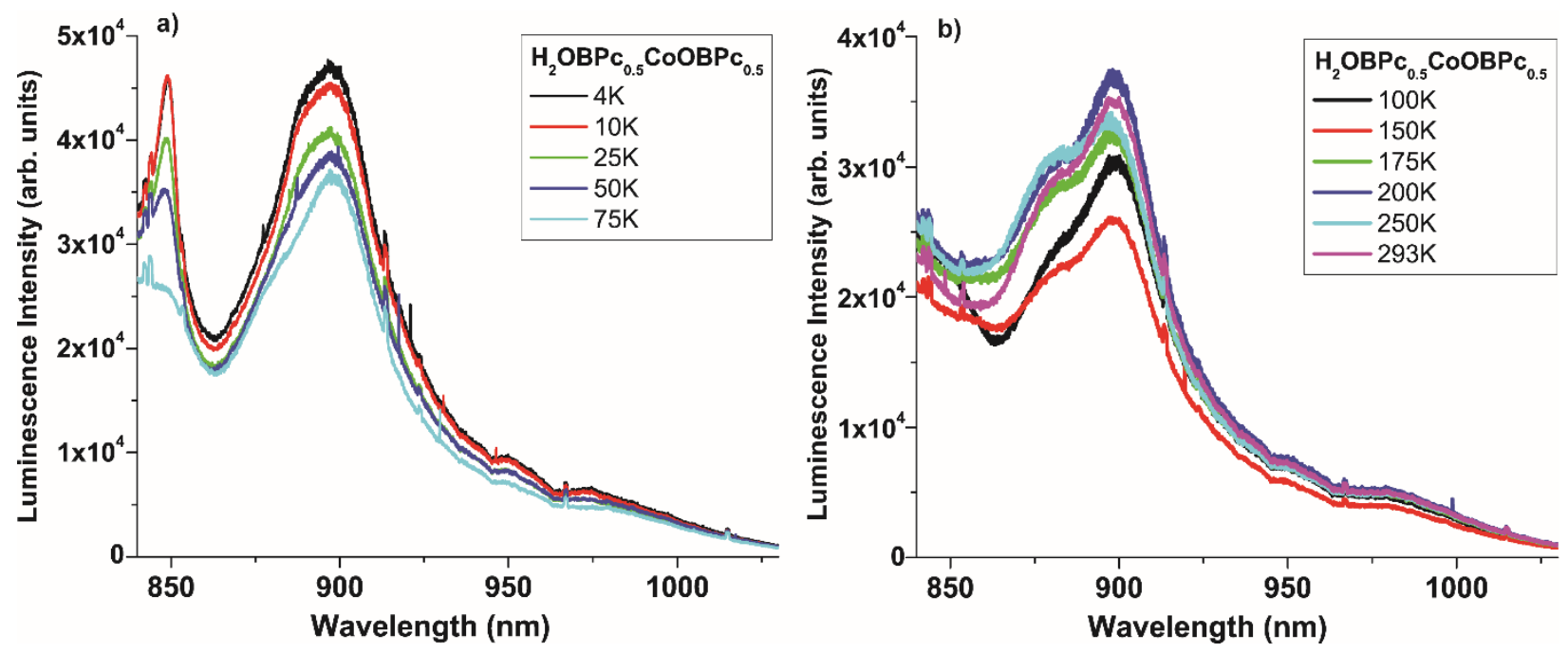

Figure S6. Temperature-dependent luminescence of a crystalline thin film of $\mathrm{H}_{2} \mathrm{OBP} \mathrm{c}_{0.5} \mathrm{CoOBP}_{0.5}$ from a) $4 \mathrm{~K}-75 \mathrm{~K}$ and b) $100 \mathrm{~K}-293 \mathrm{~K}$.
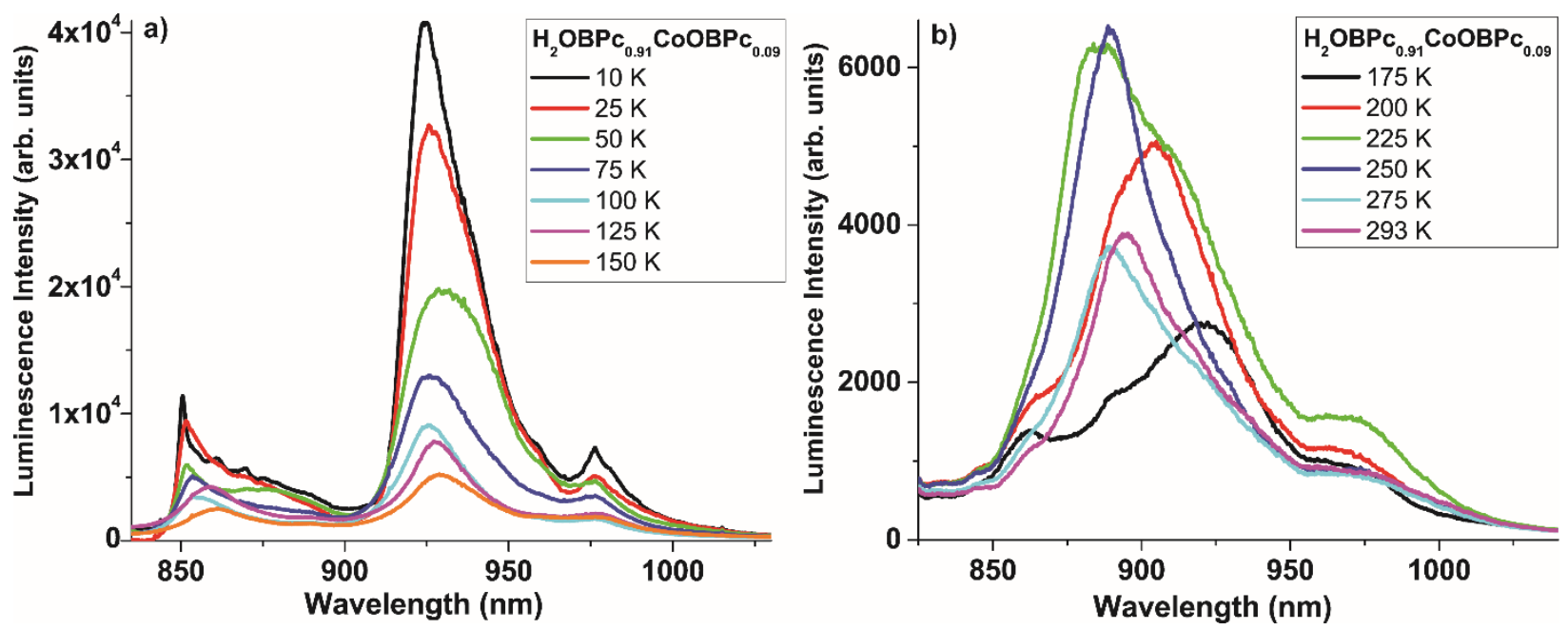

Figure S7. Temperature-dependent luminescence of a crystalline thin film of $\mathrm{H}_{2} \mathrm{OBP} 0.91$ CoOBPco.09 from a) $4 \mathrm{~K}-150 \mathrm{~K}$ and b) $175 \mathrm{~K}-293 \mathrm{~K}$. 

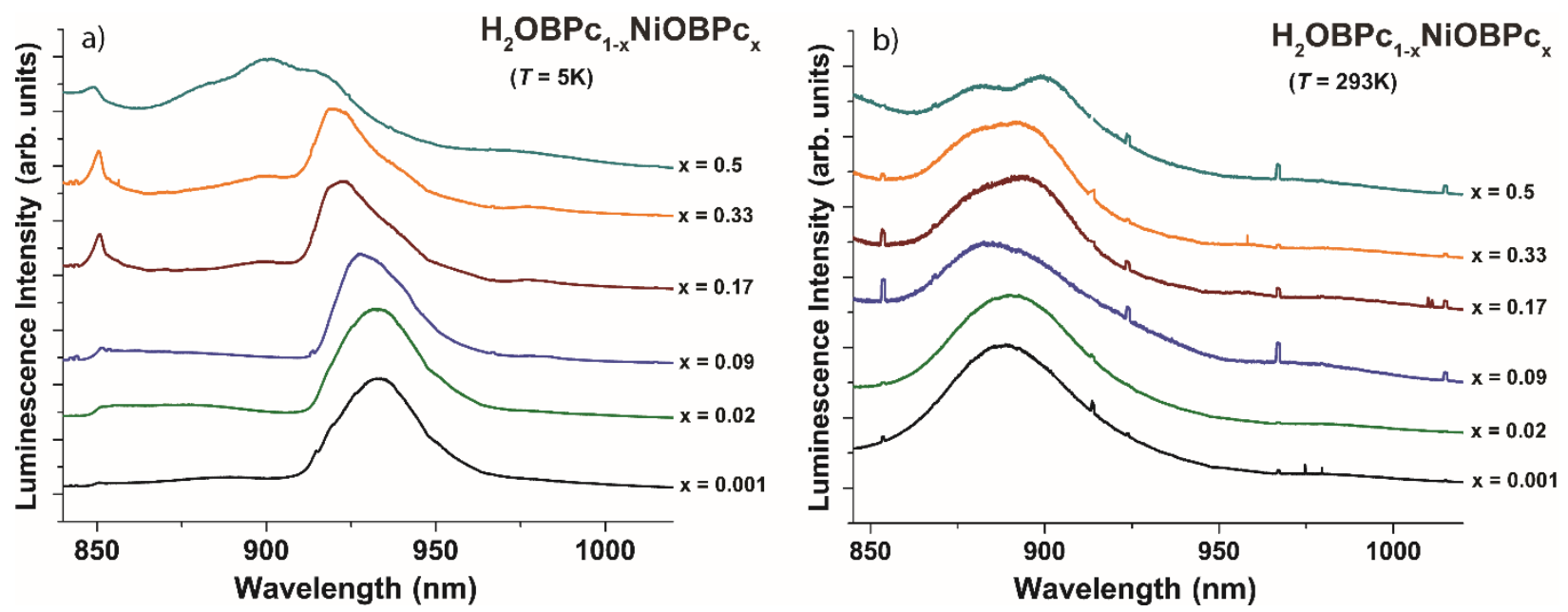

Figure S8. a) Luminescence spectra of six different concentrations of $\mathrm{H}_{2} \mathrm{OBP}_{1-x} \mathrm{NiOBP}_{\mathrm{x}}$ at a) 5 $\mathrm{K}$ and $\mathrm{b}$ ) room temperature. The corresponding concentrations of NiOBPc are listed next to each spectrum.
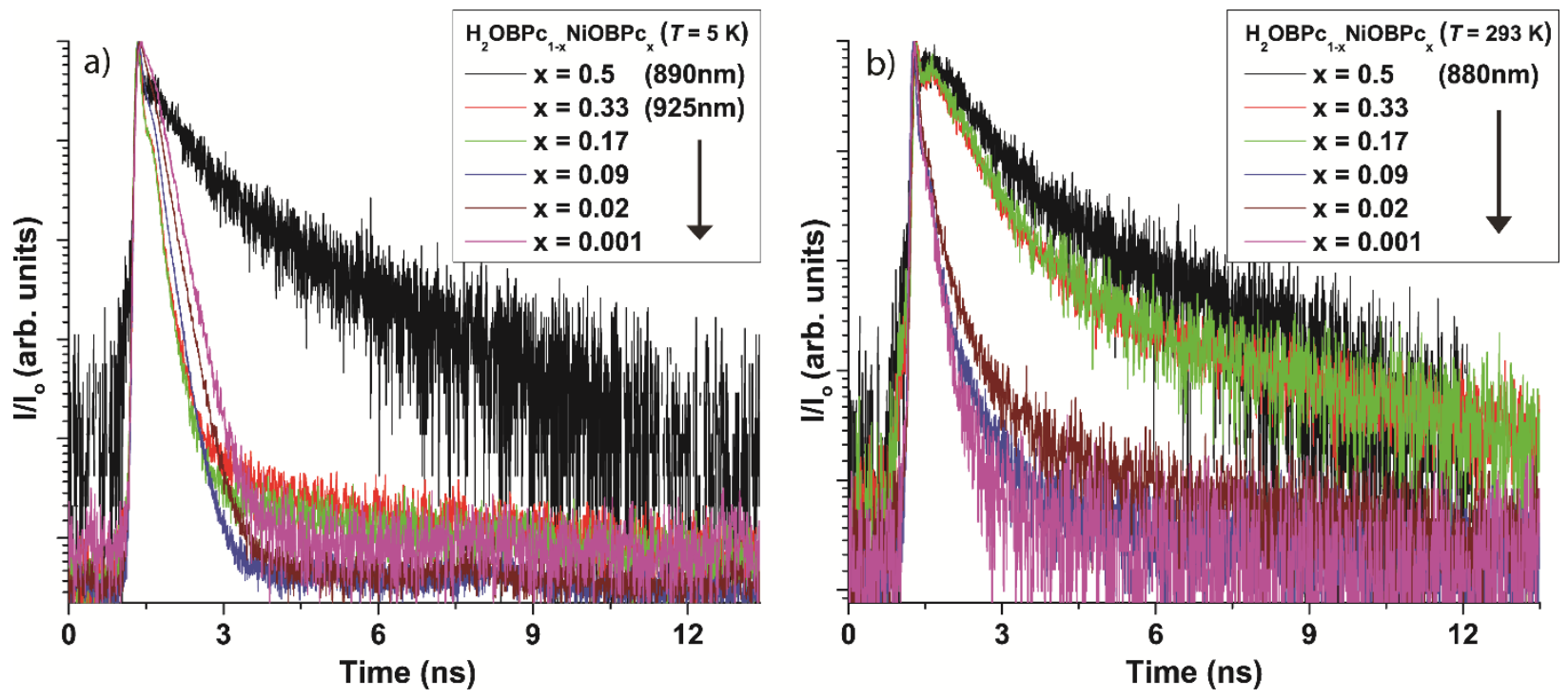

Figure S9. a) Time-resolved delocalized excitonic photoluminescence decay of six different ratios of $\mathrm{H}_{2} \mathrm{OBPc}_{1-\mathrm{x}} \mathrm{NiOBP}_{\mathrm{x}}$ at a) $5 \mathrm{~K}$ and b) room temperature. The corresponding concentrations of NiOBPc are listed in the legend. 

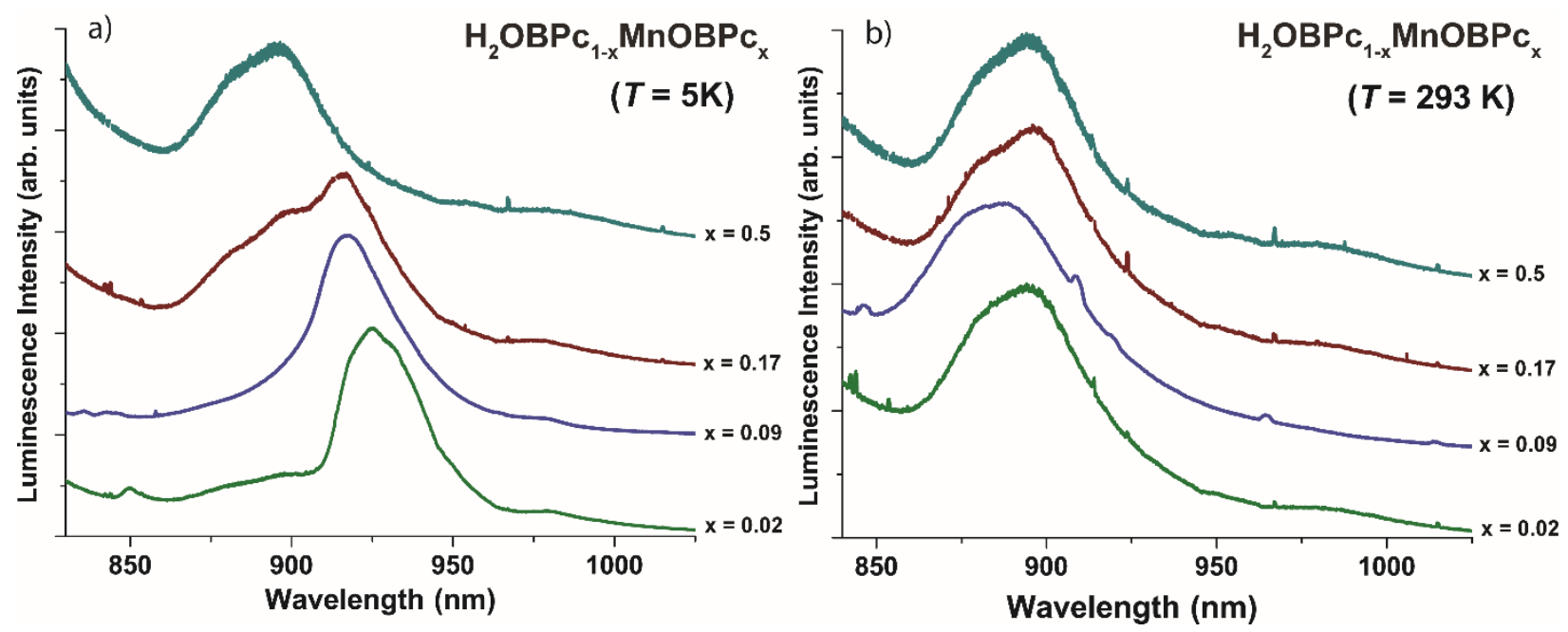

Figure S10. a) Luminescence spectra of four different ratios of $\mathrm{H}_{2} \mathrm{OBP}_{1-\mathrm{x}} \mathrm{MnOBP}_{\mathrm{x}}$ at a) $5 \mathrm{~K}$ and b) room temperature

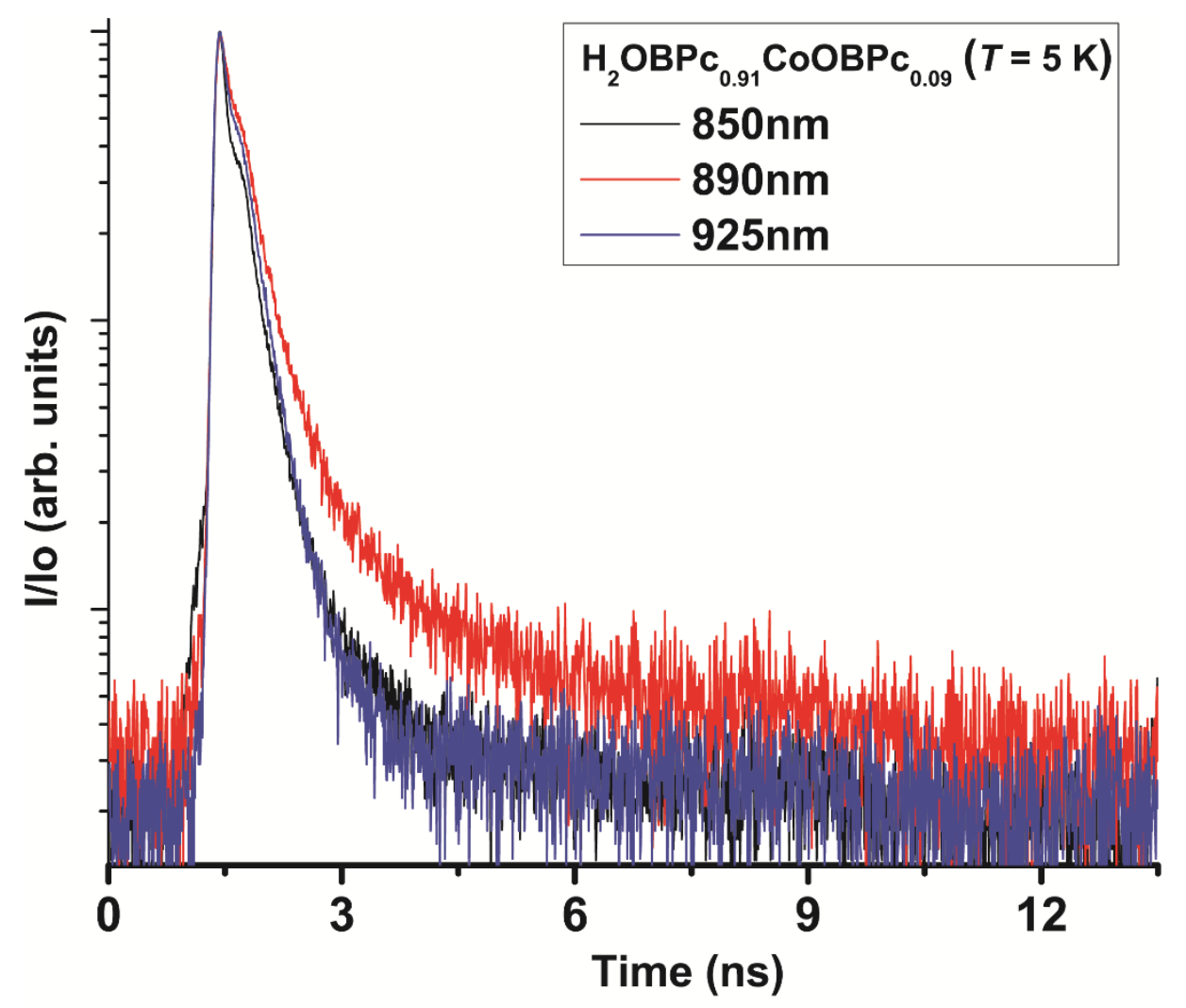

Figure S11. Time-resolved excitonic photoluminescence decay for the three features present in the $\mathrm{H}_{2} \mathrm{OBP} \mathrm{c}_{0.91} \mathrm{CoOBP}_{0.09}$ film spectrum at $5 \mathrm{~K}$ 